\title{
Negros, pardos y morenos en el Ejército Auxiliar del Perú (1810-1820)*
}

\begin{abstract}
Alejandro Morea
Jefe de Trabajos Prácticos de la Facultad de Ciencias Económicas y Sociales de la Universidad Nacional de Mar del Plata (Argentina) e Investigador Asistente del Consejo Nacional de Investigaciones Científicas y Técnicas - CONICET (Argentina). Correo electrónico: alemorea@hotmail.com. El autor es doctor en Historia por la Universidad Nacional del Centro de la Provincia (Argentina). Entre sus publicaciones recientes tenemos: "Los oficiales del Ejército Auxiliar del Perú en la construcción de los estados provinciales, 1820-1831" Revista Digital de la Escuela de Historia, Vol. 9 No. 19 (2017). Entre sus temas de interés se encuentran la historia política de la primera mitad del siglo XIX en el Río de la Plata; los ejércitos de la revolución; la construcción de los estados provinciales durante el período de las autonomías (1820-1853) y el cruce entre ejército y la construcción de carreras políticas.
\end{abstract}

Recibido: 29 de marzo de 2019

Aprobado: 10 de mayo de 2019

Modificado: 29 de mayo de 2019

Artículo de investigación científica

DOI: http://dx.doi.org/10.15648/hc.35.2019.2

* Este artículo forma parte del proyecto "Juegos de capitales. Actores y recursos en tiempo de construcción estatal, Argentina Siglo XIX (Parte II)” financiado por la Secretaría de Ciencia y Técnología, Universidad Nacional de Mar del Plata (Argentina).

Esta publicación está bajo una licencia Creative Commons Reconocimiento-NoComercial 4.0 
Negros, pardos y morenos en el Ejército Auxiliar del Perú (1810-1820)

\title{
Resumen:
}

El presente artículo busca ahondar en la participación de la población afromestiza en el Ejército Auxiliar del Perú durante las llamadas "guerras de independencia": A partir de los Estados de Fuerza, y también de la bibliografía existente, se buscará tratar de reconstruir cuántos fueron efectivamente los negros, pardos y morenos, libres y esclavos, que pasaron por el Ejército Auxiliar, y las políticas de reclutamiento llevadas adelante por los gobiernos de la revolución.

Palabras clave: Ejército Auxiliar del Perú, afromestizos, reclutamiento, esclavos, libertos.

Black, pardo, and brown people in the Auxiliary Army of Peru (1810-1820)

\begin{abstract}
This article seeks to delve into the participation of Afromestizo population in the Auxiliary Army of Peru during the so-called "wars of independence": From the States of Force, and also from the existing bibliography, we will try to reconstruct how many were effectively the blacks, brown and brown, free and slaves, who went through the Auxiliary Army, and the recruitment policies carried out by the governments of the revolution.
\end{abstract}

Keywords: Auxiliary Army of Peru, afromestizos, recruitment, slaves, freedmen

Negros, pardos e morenos no Exército Auxiliar do Peru (1810-1820).

\section{Resumo}

Este artigo busca aprofundar na participação da população Afromestiza no Exército Auxiliar do Peru durante as chamadas "guerras de independência": Desde os Estados de força e também da bibliografia existente, procuraremos reconstruir quantos eram efetivamente os negros, pardos e morenos, livres e escravos, que passaram pelo Exército Auxiliar e as políticas de recrutamento realizadas pelos governos da revolução.

Palavras-chave: Exército Auxiliar do Peru, Afromestizos, Recrutamento, Escravos, Libertos. 


\section{Noirs, Métis Et Bruns Dans L’armée Auxiliaire Du Pérou (1810-1820)}

\section{Résumé:}

Le présent article vise à approfondir dans la participation de la population afro-métisse à l'Armée auxiliaire du Pérou au cours des ce qu'on a appelé "guerres d'indépendance": À partir des États de Force, mais aussi de la littérature existante, on cherchera à reconstruire combien ont été effectivement les noirs, les métis et bruns, libres et esclaves, passés par l'armée auxiliaire, et les politiques de recrutement menées par les gouvernements de la révolution.

Mots clés: Armée auxiliaire du Pérou, Afro-métis, recrutement, esclaves, libertés.

\section{INTRODUCCIÓN}

El Ejército Auxiliar del Perú puede ser pensado como la unidad militar más importante de las Provincias Unidas del Río de la Plata durante el proceso revolucionario. No tanto por sus logros militares, donde el balance arroja claroscuros, y quizás menos como encarnación de los mejores valores e ideales de la revolución, en donde el Ejército de Los Andes en la comparación obtenga mejores resultados. Pero si pensamos en lo dilatado de su actuación, en la cantidad de hombres que pasaron por sus filas, en los roles, funciones y objetivos que le fueron encargados y en lo imbricado que estuvo su devenir con el de la revolución misma esta afirmación no resulta tan temeraria ${ }^{1}$.

En los últimos años, es posible ver un mayor interés por volver a analizar y estudiar a las fuerzas de guerra durante el proceso revolucionario. Eso puede constatarse a partir de verificar la gran cantidad de artículos y libros publicados recientemente y que abordan diferentes cuestiones sobre las

1 Alejandro Morea, "El Ejército Auxiliar del Perú y la revolución en el Río de la Plata", en Belicosas Fronteiras. Contribuições recentes sobre política, economia e escravidão em sociedades americanas (século XIX), ed. Jonas Vargas (Porto Alegre: FI, 2017), 67-89. 
tropas regulares pero también milicianas ${ }^{2}$. Desde la preocupación por su formación, las formas de reclutamiento, la relación con la sociedad, hasta cuestiones que tienen que ver con la parte más bélica, como por ejemplo el interés por reconstruir ciertas batallas desde una óptica renovada. Un aspecto no menos importante es también la relación de estas fuerzas con los procesos políticos y las disputas internas. Aunque los trabajos se multiplican, aún no tenemos nuevas historias integrales o totales sobre estas fuerzas de guerra de la revolución, principalmente porque sobre algunas cuestiones aún no sabemos tanto. En este contexto, lo que ocurre con el Ejército Auxiliar del Perú no es la excepción.

En el caso particular de esta fuerza quizás algunas de las mayores ausencias sigan siendo las investigaciones que aborden de manera sistemática e integral la composición y su integración. Por ahora solo tenemos resultados parciales y fragmentarios para la tropa y el cuerpo de oficiales ${ }^{3}$. Pero esta es una cuestión recurrente para los ejércitos de la revolución, y en gran parte se debe a que no existen estados de fuerza completos, que las situaciones de revista de los regimientos y batallones están incompletos, muy deteriorados o dispersos en diferentes repositorios documentales e incluso a cuestiones que tienen que ver con el mismo proceso histórico como la tardía organización de un Estado Mayor Conjunto para la revolución. Teniendo en cuenta esto, no es difícil comprender que solo tengamos relativamente pocos datos sobre la cantidad de hombres que pasaron por las distintas fuerzas de la revolución y que tampoco tengamos análisis que

2 Raúl Fradkin, “Tradiciones militares coloniales. El Río de la Plata antes de la revolución”, en Experiências nacionais, temas transversais: subsídios para uma história comparada da América Latina, ed. Flavio Heinz (São Leopoldo: Editora Oikos, 2009); Gabriel Di Meglio, "Soldados de la Revolución. Las tropas porteñas en la guerra de independencia (1810-1820)”, Anuario IHES 18 (2003); Alejandro Rabinovich, "Obedecer y comandar. La formación de un cuerpo de oficiales en los ejércitos revolucionarios del Río de la Plata, 1810-1820”, Estudios Sociales, (2011); Juan Carlos Garavaglia, "Ejército y milicia: los campesinos bonaerenses y el peso de las exigencias militares, 1810-1860", Anuario IHES 18 (2003): 153-87.

3 Virginia Macchi, "Guerra y política en el Río de la Plata: el caso del Ejército Auxiliar del Perú (18101811)", Anuario de la Escuela de Historia Virtual 3 (2012): 78-96; Alejandro Morea, "Soldados para la Independencia. Algunas notas sobre las características del cuerpo de oficiales del Ejército Auxiliar del Perú”, Nuevo Mundo Mundos Nuevos [En línea], (2013), tp://nuevomundo.revues.org/65195; DOI : 10.4000/nuevomundo.65195; Marisa Davio, "El proceso de militarización en Tucumán: experiencias e identidades de los sectores populares”, Historia y Memoria, (2011): 93-96. 
prioricen algún tipo de recorte socio-ocupacional, por lugar de nacimiento o color de piel.

Para el Ejército Auxiliar del Perú esto es bastante palpable. A diferencia del Ejército de Los Andes donde tenemos cifras aproximadas, para el Auxiliar desconocemos la cantidad de pardos y morenos que lo integraron a lo largo de sus diez años de existencia. Pero no solo esto, en realidad son pocos los trabajos que se han enfocado en dar cuenta de la experiencia de los negros en esta fuerza militar y en el espacio altoperuano. Lo que no quiere decir que no existan trabajos parciales y puntuales sobre los afroargentinos en las guerras de Independencia ${ }^{4}$. Por eso, a partir de la bibliografía existente, de la documentación del período que se encuentra en el Archivo General de la Nación y en el Servicio Histórico del Ejército, trataremos de hacer un primer abordaje sobre la participación de pardos y morenos, uno de los grupos poblacionales más importantes del Virreinato del Río de la Plata para 1810, en el Ejército Auxiliar del Perú, con especial énfasis en tratar de reconstruir, desde las cifras, la participación de esto hombres en dicho ejército.

\section{Batallones y Regimientos de afromestizos en el Ejército Au- xiliar del Perú}

El Ejército Auxiliar del Perú a lo largo de sus casi diez años de existencia sufrió varias reorganizaciones desde su primera estructuración como expedición de auxilio a las provincias interiores con base en las milicias y las tropas veteranas existentes en la ciudad de Buenos Aires hacia junio de 1810. Las unidades que lo integraron fueron cambiando con el correr de los años al compás de las propuestas de los comandantes en jefe, de las disposiciones del gobierno, pero también por la dinámica de la guerra que muchas veces determinó el fin de algunos regimientos y batallones,

4 Para un recorrido sobre la producción sobre esta temática se puede consultar: Carmen Bernand, "Los olvidados de la revolución: el Río de la Plata y sus negros", Nuevo Mundo Mundos Nuevos. Nouveaux mondes Mondes nouveaux - Novo Mundo Mundos Novos - New world New worlds, (2010), https://doi.org/10.4000/nuevomundo.58416; Florencia Guzmán, "Afroargentinos, guerra y política, durante las primeras décadas del siglo XIX. Una aproximación hacia una historia social de la revolución”, Estudios Históricos - CDHRPyB 11 (2013). 
pero también del cambio de las alianzas y espacios controlados por las armas de la revolución, que en algunas ocasiones también dotó o privó de unidades al ejército con un determinado componente geográfico ${ }^{5}$. Incluso es difícil seguir el rastro de las mismas unidades por los cambios de nombres y nomenclaturas, porque muchas veces tienen homónimos en algún otro punto de las Provincias Unidas del Río de la Plata. Acá podemos ver efectivamente la ausencia de un estado mayor en los primeros años del proceso que fijara las directrices sobre cómo denominar a las unidades de combate y estableciera

Algo similar podemos decir con respecto a la cantidad de efectivos con los que contó este ejército. Su número varió mucho en función de las circunstancias de la guerra, pero sobre todo en función de la estrategia militar implementada por los distintos gobiernos revolucionarios que se sucedieron hasta 1820, incrementando los soldados y recursos disponibles en función de los objetivos que se perseguían. En este sentido, cada traspié sufrido por el Ejército Auxiliar del Perú significó una gran desorganización y pérdida de soldados, oficiales, pertrechos, etc. Lo primero siempre más sencillo de resolver que lo segundo.

A grandes rasgos, los ejércitos de la revolución se manejaron observando las Ordenanzas Militares de Carlos III y sus modificatorias ${ }^{6}$. Aunque a veces llevaran el nombre de regimientos las unidades que por sus efectivos no debían pasar de un batallón o al revés, regimientos que excedían la cantidad de plazas, las ordenanzas eran la base sobre la cual se organizaron las fuerzas de la revolución. Por esa razón en lo ateniente a los negros, pardos y morenos inicialmente se continuó con la práctica del período colonial: la incorporación de estos hombres, siempre que fueran libres, en unida-

5 Un claro ejemplo de esto ocurrió durante la primera campaña al Alto Perú cuando en los momentos previos de la Batalla de Huaqui el Ejército tomó el nombre de Ejército Auxiliar y Combinado del Perú tras la incorporación de las unidades militares de Cochabamba. Cfr. Alejandro M. Rabinovich, Anatomía del pánico. La batalla de Huaqui, o la derrota de la revolución (1811) (Buenos Aires: Sudamericana, 2017), 115.

6 Alejandro Rabinovich, "Obedecer y comandar".; Alejandro Morea, "El proceso de profesionalización del Ejército Auxiliar del Perú durante las guerras de independencia", Revista Quinto Sol 15, n.o 2 (2011): 73-96; Alejandro Morea, "Perfil de los oficiales del Ejército Auxiliar del Perú en el contexto revolucionario rioplatense, 1810-1820", Hib: Revista de Historia Iberoamericana 8, No 2 (2015): 102-31, https://doi.org/10.3232/HIB.2015.V8.N2.05; Raúl Fradkin, “Tradiciones militares coloniales". 
des segregadas al mando de oficiales blancos en regimientos de "castas" . Sin embargo, en el nuevo contexto político y de ideas, esto fue puesto en cuestión y revisado. Y aunque tendremos unidades exclusivas de negros, veremos que muchos hombres de color se integraron a regimientos que se formaron como de hombres blancos y blancos revistiendo en unidades que fueron pensadas de negros ${ }^{8}$. Por otro lado, la bibliografía existente señala que muchos negros, pardos y morenos accedieron a la oficialidad ${ }^{9}$. No obstante, siempre perduró cierta resistencia por parte de los actores a dar paso a una completa integración e igualación entre afromestizos y blancos como veremos más adelante.

En el caso del Ejército Auxiliar, rápidamente podemos identificar cuáles fueron las unidades de afromestizos a lo largo de sus diferentes campañas. En este sentido, la derrota sufrida en Sipe-Sipe fue también un parteaguas con respecto a esta cuestión como lo fue para el objetivo que debía cumplir y el espacio en el que se desempeñaría el ejército ${ }^{10}$. La casi total aniquilación de las unidades de negros y la deserción de muchos de los que sobrevivieron a Sipe-Sipe, significó el fin de la presencia de unidades específicas de negros, pardos y afromestizos en el Ejército Auxiliar. Los que se mantuvieron en el ejército fueron integrados en otras unidades.

En la primera expedición del Ejército Auxiliar revistieron dos compañías de pardos y morenos que habían sido extraídas de la unidad existente en la capital previo al inicio de la revolución ${ }^{11}$. A diferencia de las otras compañías sueltas de infantería de los diferentes regimientos existentes en la capital y que pasaron a integrar el Regimiento de Infantería $\mathrm{N}^{\circ}$ 6, estas compañías de pardos y morenos se mantuvieron segregadas ${ }^{12}$. Recién en diciembre de 1812 y bajo la conducción de Manuel Belgrano, esta fuerza

\footnotetext{
7 George Reid Andrews, Los Afroargentinos de Buenos Aires, 1er ed. (Argentina: Ediciones de la flor, 1989), 142-43.

8 George Reid Andrews, Los Afroargentinos,143.

9 George Reid Andrews, Los Afroargentinos, 150.

10 Alejandro Morea, "El Ejército Auxiliar del Perú y la gobernabilidad del interior, 1816-1820”, ProHistoria, Año XV, 18 (2012): 26-49.

11 Diego Alejandro Soria, "Las grandes unidades de batalla", en Guerra de la Independencia. Una nueva versión, ed. Miguel Ángel De Marco (Buenos Aires: Emecé Editores, 2013), 110.

12 Alejandro Rabinovich, Obedecer y comandar..., 87.
} 
fue elevada a Batallón con la llegada de entre 70 y 80 pardos y morenos provenientes de Buenos Aires ${ }^{13}$. Este Batallón de Pardos tuvo existencia hasta 1814 cuando tras las aplastantes derrotas en Vilcapugio y Ayohuma se disolvió y sus efectivos pasaron a incorporarse al Batallón de Infantería $\mathrm{N}^{\mathrm{o}} 7^{14}$. El Batallón de Pardos y Morenos era, en teoría, una unidad compuesta de hombres libres o que al menos lo eran antes de su enlistamiento.

La segunda unidad de hombres de color que se integró al Ejército Auxiliar fue el Regimiento de Infantería $N^{\circ} 6$ (de pardos) para diferenciarlo de su homónimo que ya había existido en esta fuerza durante la primera campaña al Alto Perú, pero que era integrada por hombres blancos. Esta unidad de negros había sido creada para actuar en la Banda Oriental pero en 1812 fue destinada al frente altoperuano. Estaba compuesta de hombres libres también ${ }^{15}$.

En 1814, tras las derrotas de Vilcapugio y Ayohuma estas dos unidades, desaparecieron de la estructura del Ejército Auxiliar de Perú y sus hombres fueron integrados a una nueva unidad de hombres afromestizos, el Batallón de Infantería $N^{0} 7$, llegado con el nuevo general en jefe José de San Martín ${ }^{16}$. La característica de esta unidad es que estaba integrada, en teoría, exclusivamente por libertos y se había conformado luego de los decretos de la Asamblea del Año XIII que habían impulsado un amplio rescate de esclavos por parte del Estado para reforzar a los distintos ejércitos de la revolución. Pero al momento de integrarse al Ejército Auxiliar se le sumaron hombres que ya eran libres. Como decíamos anteriormente, luego de Sipe-Sipe esta unidad desapareció y el Ejército Auxiliar del Perú se quedó sin unidades específicamente integradas por afromestizos. Lo que no quiere decir que desaparecieran los hombres de color de esta fuerza militar, cuestión sobre la que volveremos más adelante.

13 Diego Alejandro Soria, "Las grandes unidades de batalla", 112.

14 Diego Alejandro Soria, "Las grandes unidades de batalla", 112.

15 Julio Luqui-Lagleyze, "La organización general y particular del Ejército de las Provincias Unidas del Río de la Plata, 1810-1820”, en Guerra de la Independencia. Una nueva versión, ed., Miguel Ángel De Marco (Buenos Aires: Emecé Editores, 2013), 161.

16 Julio Luqui-Lagleyze, La organización general 161. También hace referencia a esto el Estado de fuerza firmado por San Martín en Tucumán el 27 de febrero de 1814, Archivo General de la Nación (AGN), Sala X, Legajo 3-8-6 Ejército Auxiliar del Perú. 
Igualmente la cuestión no es tan lineal. La presencia de hombres de color en el Ejército Auxiliar no se reduce a estas unidades específicas. Hay registro de otros regimientos que estuvieron integrados, al menos parcialmente, por afromestizos. En 1814 también, ya durante la conducción de José Rondeau, el gobierno envió uno de los batallones del Regimiento de Infantería $\mathrm{N}^{\circ} 2$ a reforzar los efectivos del Ejército Auxiliar del Perú. Originalmente conformado para actuar en el sitio de Montevideo, este batallón fue conformado con dos compañías de pardos y morenos que aún subsistían en la capital y un piquete de artillería también integrado por negros. Luego de la capitulación, esta unidad fue destinada al Alto Perú, pero luego del amotinamiento de diciembre de 1814, fue desintegrada y sus efectivos repartidos en el resto de los regimientos existentes ${ }^{17}$.

Lo que no podemos saber, por el momento, es efectivamente cuántos afromestizos tenían esas dos compañías ni tampoco a qué unidad fueron integrados una vez disuelto el $\mathrm{N}^{\circ}$ 2. Si esta cuestión, la de determinar cuáles fueron efectivamente los regimientos y batallones de afromestizos que integraron el Ejército Auxiliar resulta relativamente sencilla, no lo es tanto tratar de establecer el número de hombres de color que pasaron por sus filas. Este tipo de situaciones, la presencia de afromestizos por fuera de los regimientos que teóricamente estaban integradas por hombres de color, solo suma complejidad a una tarea ya de por sí ardua. Si estas dos compañías se encontraban con sus plazas completas y se respetaban los reglamentos, podemos decir que al menos dentro de ese batallón del $\mathrm{N}^{\circ}$ 2 teníamos 200 soldados afromestizos que pasaron a integrar alguna otra unidad pero es difícil asegurarlo. No bastará entonces con sumar los efectivos de los regimientos de afromestizos a estos 200 hombres que intuimos que estaban en el $\mathrm{N}^{\circ} 2$.

Como decíamos previamente, esto no es una cuestión de estas unidades en particular, sino una problemática más bien general por la incertidumbre en la que nos manejamos para establecer cuál fue el número total de hombres

17 Julio Luqui-Lagleyze, La organización general 162; José Rondeau, Autobiografía (Comercio del Plata, 1846), 48. 
que integraron el Ejército Auxiliar, por lo fragmentario de nuestro acervo documental pero además por el sesgo que presentan las fuentes con las que estamos haciendo esta primera aproximación a la temática.

La fuente principal de información con la que trataremos de construir los datos con los que vamos a abordar la temática la constituyen los Estados de Fuerza y Armamentos que los distintos comandantes elaboraron de forma periódica y que eran enviados al gobierno central. En estos Estados de fuerza podemos encontrar la cantidad de efectivos totales que tenía el Ejército el día de la revista y el desagregado por batallones y regimientos, distinguiendo entre oficiales y tropa. Por supuesto que estos documentos no especifican la composición de los regimientos y tampoco qué compañías se encontraban completas pero, sabiendo cuáles son las unidades de afromestizos, podemos tratar de dar cuenta de cuántos eran estos individuos, en relación al total declarado en diferentes momentos, pero no afirmar que la cantidad de afromestizos en el Ejército Auxiliar del Perú se resuma a estas unidades segregadas.

No obstante, para unos períodos tenemos mayor cantidad de información que para otros. Muy fragmentaria es la documentación para la primera expedición al Alto Perú y para la realizada bajo órdenes de José Rondeau entre 1814 y 1815 cuando quizás tuvieron lugar las peores derrotas de la revolución (Huaqui y Sipe-Sipe). Esto puede deberse en parte a la falta de organización de la administración, como decíamos previamente, pero también a la pérdida de la documentación en los retrocesos que se dieron de forma caótica. El contraste es lo ocurrido con los dos momentos en que el Ejército Auxiliar del Perú estuvo conducido por Manuel Belgrano, entre 1812 y 1814 , y entre 1816 y 1819, donde podemos hacer un seguimiento mucho más completo, y también en los meses que estuvo bajo órdenes de José de San Martín en 1814. Por lo tanto, esta reconstrucción que pasaremos a realizar tiene un sesgo producto de las fuentes, pero también

34 por las lagunas existentes en esa misma documentación. A pesar de esto, podremos obtener algunas cifras aproximadas con las cuales intentar sacar algunas conclusiones parciales. 


\section{2. ¿Cuántos afromestizos pasaron por el Ejército Auxiliar del Perú?}

La expedición que se conformó en Buenos Aires con destino a las provincias interiores tuvo inicialmente 1.176 hombres. De los cuales creemos que hasta 200 pueden haber sido afromestizos de las dos compañías de Pardos y Morenos que integraron este ejército aunque lo más probable es que no haya superado las 100 plazas. Con el correr de los meses las fuerzas del Ejército Auxiliar del Perú se incrementaron hasta alcanzar, en los momentos previos a la batalla de Huaqui, a casi los 6.000 hombres. Alejandro Rabinovich, quien ha estudiado con detalle lo ocurrido en Huaqui, sostiene que el Ejército Auxiliar del Perú tenía 4.626 hombres de tropas más 190 oficiales distribuidos en los principales regimientos del Ejército y que a eso se podrían sumar los efectivos de algunas compañías sueltas, lo que arroja un total de 5.900 hombres. Entre esas compañías sueltas señala las dos de Pardos y Morenos provenientes de Buenos Aires y una de Pardos de Córdoba y a las cuales les atribuye un promedio de 50 hombres por compañía, lo que nos da un total aproximado de 150 hombres de color ${ }^{18}$.

Luego de lo ocurrido a orillas del río Desaguadero, el Ejército Auxiliar del Perú quedó casi desintegrado por lo cual no resulta extraño que sus efectivos totales se redujeron considerablemente. El coronel Viamonte, jefe del Regimiento de Infantería $\mathrm{N}^{\circ}$ 6, luego de Huaqui quedó provisoriamente al mando del Ejército hasta que se hizo cargo de él el general Pueyrredón. En el Estado de Fuerza que se confeccionó luego de la revista que se pasó en Jujuy el 14 de octubre de 1811 podemos observar que el Ejército Auxiliar tenía 843 efectivos de los cuales 783 eran de tropa y el resto oficiales. En ese contexto, el Estado de Fuerza consigna la existencia de una unidad de Pardos y Morenos con 89 hombres de los cuales solo 7 serían oficiales. Nada se dice de la compañía de Pardos de Córdoba que había integrado esta fuerza previa a Huaqui.

Cuando Juan Martín de Pueyrredón tomó el mando del Ejército Auxiliar

18 Alejandro Rabinovich, Obedecer y comandar..., 76. 
del Perú se produjo una disminución de los efectivos de Pardos y Morenos. En la revista del 1 de diciembre de 1811 estas compañías sólo tienen 43 soldados y 3 oficiales aunque la cantidad de hombres del ejército comienza a incrementarse llegando a 1734 hombres en total. Solo con la llegada de Belgrano los efectivos de Pardos y Morenos parecen incrementarse. En el primer Estado de Fuerza con el que contamos podemos ver que en la revista realizada en Campo Santo a fines de abril de 1812 el cuerpo de Pardos y Morenos tiene 305 individuos de tropa y 11 oficiales cuando en el Ejército tenemos 1.588 hombres. En torno a los 300 efectivos de tropa se mantuvieron estas compañías, elevadas a Batallón luego de diciembre de 1812 por Belgrano. Lo que no se mantiene constante es el número de efectivos del Ejército. A mediados de 1813, luego de los éxitos en las Batallas de Tucumán y Salta, el Ejército Auxiliar del Perú tenía 3.464 hombres.

Pero también, como dijimos anteriormente, el Regimiento de Infantería N 6 (de Pardos) se sumó al Ejército Auxiliar del Perú. A fines de 1812 tenían 792 hombres de tropa con 39 oficiales y luego de la Batalla de Salta 1.021 hombres entre soldados y suboficiales y 52 oficiales. La derrota en octubre de 1813 en la Batalla de Vilcapugio fue un cimbronazo importante, porque el número total de efectivos se redujo a solamente 2.000 hombres y los regimientos de afromestizos sintieron el golpe. El $\mathrm{N}^{\circ} 6$ quedó reducido a 387 hombres de los cuales 32 eran oficiales y el de Pardos y Morenos tenía 197 individuos de tropa y 13 oficiales.

Luego de esto, Manuel Belgrano incrementó la recluta en la zona para tratar de suplir las bajas. En la revista realizada en las Pampas de Ayohuma, el 12 de noviembre de 1813, dos días antes de la Batalla de Ayohuma en la que las fuerzas de la revolución salieron nuevamente derrotadas, el número total de efectivos del Ejército Auxiliar ascendía a 4.159, alcanzando unos de sus máximos. El Batallón de Pardos y Morenos mantuvo casi constante su número de efectivos con 198 soldados y suboficiales y

3615 oficiales. Pero el Regimiento $\mathrm{N}^{\circ} 6$ recuperó parcialmente su fuerza: su número total llegó a los 605 con 566 hombres de tropa. Los nuevos reclutas del $\mathrm{N}^{\circ} 6$ ¿ंeran efectivamente afromestizos? Imposible saberlo en este 
momento. La derrota en Ayohuma fue aún más dura que la de Vilcapugio y en la revista realizada por Belgrano en Jujuy a principios de enero de 1814 se puede ver esto: el Ejército contaba tan solo con 1.940 hombres, el Batallón de Pardos y Morenos tenía 188 hombres de tropa con 14 oficiales y el $N^{\circ} 6244$ soldados y suboficiales con 21 oficiales.

La llegada de José de San Martín a la conducción del Ejército Auxiliar con un refuerzo de tropa proveniente de Buenos Aires y el estado en que se encontraban algunas de las unidades de esa fuerza fue lo que llevó a una reestructuración del Ejército, que en gran medida, afectó a las unidades de afromestizos. En el primer estado de fuerza realizado en San Miguel de Tucumán, en febrero de 1814, San Martín informa que 54 soldados del Batallón de Pardos y Morenos y del Regimiento de Infantería $N^{\circ} 1$ fueron incorporados en el Regimiento de Infantería $\mathrm{N}^{\circ} 7$ que había sido agregado recientemente al Ejército Auxiliar y que estaba integrado, en su mayoría, por libertos y hombres de color libres. En un momento donde las fuerzas totales ascendían a 2.949 hombres, el $\mathrm{N}^{\circ} 7$ tenía 785 individuos de tropa y 32 oficiales. Ese número fue incrementándose hasta alcanzar los 836 individuos de tropa con 26 oficiales en agosto de 1814 cuando el Ejército ya tenía en total 3.117 hombres.

El problema a partir de este momento es que la información con la que disponemos es sumamente fragmentaria. Como ya indicamos, los Estados de Fuerza durante la conducción de Rondeau no son muy numerosos y algunos de los disponibles son incompletos. Lo que podemos afirmar es que al promediar el año 1814 el Regimiento $N^{\circ} 7$ tenía un total de 842 hombres de los cuales 32 eran oficiales y el resto tropa. Poco más es lo que podemos decir al respecto. La mayoría de los relatos sobre la tercera campaña del Ejército Auxiliar del Perú coinciden en que al momento de la Batalla de Sipe-Sipe, en noviembre de 1815, los efectivos de esta fuerza ascendían hasta los casi cuatro mil hombres ${ }^{19}$. Luego del enfrentamiento y

19 Bartolomé Mitre, Historia de Belgrano y de la independencia argentina, 1a ed. (Buenos Aires: El Ateneo, 2014), 447; Isidoro Ruiz Moreno, Campañas militares argentinas (Argentina: Emecé Editores, 2008), 193. 
por las bajas y deserciones, el Ejército Auxiliar quedó reducido a un poco más de mil quinientos hombres y como dijimos previamente, los restos del $\mathrm{N}^{\mathrm{o}} 7$ que contenía la mayor cantidad de afromestizos fueron distribuidos entre los Regimientos de Infantería $\mathrm{N}^{0} 3$ y $\mathrm{N}^{0} 9^{20}$. Lo que representa un gran desafío en nuestro esfuerzo por contabilizarlos, ya que no tenemos forma, por el momento, de establecer cuáles de los soldados de esas unidades son blancos y cuáles afromestizos.

Acá es donde es posible volver sobre Andrews, quien ha dado cuenta de la gran cantidad de hombres afromestizos en unidades que se presuponen blancas. Al analizar los enrolamientos de diez unidades militares que se conformaron en Buenos Aires entre 1813 y 1860 da cuenta de que en al menos seis de ellas los negros son un cuarto de los soldados enlistados y que en al menos en una de ellas llegan a los tres cuartos ${ }^{21}$. Pero no es algo que podamos generalizar para todas las unidades como el mismo autor enuncia, ya que en otras unidades solamente alcanzarían al 1 o $2 \%$ y uno de los regimientos con los que ejemplifica esta situación es el $\mathrm{N}^{\mathrm{o}} 9$ en el año $1816^{22}$. ¿De cuántos hombres entonces estamos hablando? A lo largo de ese año el número de efectivos de ese regimiento fue oscilando. En algunos momentos tuvo un poco más de 450 hombres de tropa pero la mayor parte del tiempo estuvo entre los 330 y los 360 soldados y suboficiales. Por lo que podríamos plantear que entre 30 y 40 soldados de ese regimiento eran negros. Pero sería erróneo pensar que la cantidad de negros presentes en el Ejército Auxiliar del Perú se redujo a esto o que solamente esta unidad tenía soldados afromestizos. En una fecha muy avanzada, septiembre de 1819, el Mayor General De la Cruz ordenaba que un esclavo recientemente donado por su dueño se incorporara al Batallón de Infantería $\mathrm{N}^{\mathrm{o}} 10^{23}$. Por eso es complejo poder reconstruir un panorama mínimo como quizás podemos hacer para los momentos anteriores.

23 AGN, Legajo 40-8-6, Ejército Auxiliar del Perú, 1818-1819. 
Cuadro 1: Cantidad de Efectivos en las unidades de afromestizos en relación al total de efectivos del Ejército Auxiliar del Perú ${ }^{24}$

\begin{tabular}{|c|c|c|c|}
\hline Año & Efectivos Totales & Tropas en Unidades de Afromestizos & Porcentaje sobre el total \\
\hline 1810 & 1.176 & 100 & 8,5 \\
\hline 1811 & 5.900 & 150 & 2,54 \\
\hline 1811 & 843 & 82 & 9,72 \\
\hline 1811 & 1.734 & 43 & 2,47 \\
\hline 1812 & 1.855 & 305 & 16,44 \\
\hline 1813 & 3.464 & 1326 & 38,27 \\
\hline 1813 & 2.000 & 562 & 26,3 \\
\hline 1813 & 4.159 & 764 & 18,36 \\
\hline 1814 & 1.940 & 432 & 22,26 \\
\hline 1814 & 2.949 & 785 & 26,61 \\
\hline 1814 & 3.117 & 810 & 25,98 \\
\hline 1815 & 4.000 & 810 & 20,25 \\
\hline
\end{tabular}

Teniendo en cuenta lo ya dicho, que la presencia de afromestizos no es posible reducirla solamente a estas unidades en particular, que es factible que muchos estuvieran incorporados a otras unidades, o que algunos estuvieran invisibilizados ya que muchas veces eran incorporados como trigueños, o ante la imposibilidad de poder discriminar si los oficiales de estas unidades eran todos blancos o de color, lo cierto es que los afromestizos en pocas oportunidades superaron el 30\% de los efectivos de este ejército y que las más de las veces se encontraban alrededor del 20\%, con algunos momentos donde los porcentajes son extremadamente bajos. Pero, ¿qué nos dicen estas cifras? Para responder esta pregunta es importante trazar algún tipo de comparación con otras fuerzas de la revolución pero también sería importante tratar de explicarlas teniendo en cuenta el contexto de la revolución y su política específica de reclutamiento y sin olvidarnos de la composición de esa sociedad rioplatense hacia 1810.

$24 \quad$ Los datos del cuadro se obtuvieron a partir de los Estados de Fuerza del Ejército Auxiliar del Perú que consultamos en el Archivo General de la Nación (AGN) y en el Servicio Histórico del Ejército (SHE). En AGN, Sala X; Legajos: 3-8-6; 4-1-3; 4-1-6; 4-2-2. En SHE, 1815, Ejército Auxiliar del Perú, C5; Estados de Fuerza Expedición de Auxilio a las Provincias Interiores, Ejército Auxiliar del Perú, C7. 


\section{3. ¿ ¿UN EJÉrCito Más BLANCO QUE SU SOCIEDAD?}

Al repasar los efectivos que tenía el Ejército de Los Andes antes de iniciar el cruce de la Cordillera de Los Andes para llegar a Chile en 1817, su organización y su composición, una de las cosas que más destaca es la gran cantidad de afromestizos que formaron parte de esta campaña. Los datos existentes nos permiten decir que casi la mitad de los soldados del Ejército de Los Andes estaba compuesta por afromestizos, la mayoría de ellos libertos y enrolados en los Batallones de Infantería $\mathrm{N}^{\circ} 7$ y $\mathrm{N}^{\circ} 8$. Su número ascendía a 1.554 hombres cuando el número total de soldados era de $3.778^{25}$. La cifra de negros a su vez representaba entre un $30 \%$ o un $40 \%$ del total del Ejército dependiendo con qué número nos manejemos para hacer los cálculos. La primera cifra sería si a los combatientes les sumamos a los auxiliares del Ejército de Los Andes que hace que el número total de esa fuerza militar sea de 5.423 hombres, pero si solo tenemos en cuenta a los hombres de pelea (4.016) se llega casi al 40\%.

Estos números contrastan con los repasados para el Ejército Auxiliar del Perú. Para explicar esta diferencia podríamos apelar a las muchas veces citada confrontación entre José de San Martín y Manuel Belgrano sobre la valía de los afromestizos en combate. José de San Martín se pronunciaba en estos términos en 1816 a Tomás Godoy Cruz:

“....solo nos puede salvar el poner a todo esclavo sobre las armas; por otra parte, así como los americanos son lo mejor para la caballería, así es una verdad que no son los más aptos para infantería, mire usted que yo he procurado conocer a nuestro soldado, y sólo los negros son los verdaderamente útiles para esta última arma..."26

Por el contrario, Manuel Belgrano siendo aún comandante del Ejército Auxiliar del Perú tras las derrotas de Vilcapugio y Ayohuma, y a la espera

25 John Lynch, San Martín. Soldado argentino. Héroe americano. (Barcelona: Crítica, 2009), 137.

26 Citado por Alejandro Rabinovich, Ser soldado en las Guerras de Independencia. La experiencia cotidiana de la tropa en el Río de la Plata, 1810-1824 (Buenos Aires: Editorial Sudamericana, 2013), $42-43$. 
de la llegada de San Martín con refuerzos, se franqueaba con quien a la postre sería su reemplazo de la siguiente manera:

“...No estoy contento con la tropa de los libertos, los negros y mulatos son una canalla que tiene tanto de cobarde como de sanguinaria, y en las cinco acciones que he tenido han sido los primeros en desordenar la línea, y buscar muralla de carne: sólo me consuela saber que vienen oficiales blancos, o lo que llamamos españoles..."27

Pero proceder de esta manera, sería en algún punto simplificar la cuestión. Ya que las políticas de reclutamiento, y específicamente con respecto a negros o afromestizos, no estuvieron predeterminadas únicamente por las opiniones de los comandantes sobre el desempeño de este sector de la población en el campo de batalla. En los primeros años se puso en evidencia esa tensión de la que hablábamos al inicio entre la práctica y retórica, entre los ideales discursivos de la revolución y las limitaciones concretas, reparos reales y objeciones de los actores con esas ideas.

Si desde 1810 se movilizó a los pardos y morenos libres, si las milicias que los nucleaban fueron convertidas en tropas veteranas, los primeros gobiernos revolucionarios se mostraron muy cautelosos en movilizar o intentar reclutar a los esclavos. Esta cuestión se jugaba en dos planos. Por un lado, el tradicional miedo de las autoridades y de las elites en general a armar a aquellos grupos y sectores sociales subalternos, dominados, sometidos como lo eran en este caso los esclavos ${ }^{28}$. Estos temores además se habían reactualizado a partir de lo ocurrido en la parte francesa de Santo Domingo $^{29}$. Pero también se chocaba con otro obstáculo no menos im-

27 Academia Nacional de la Historia, Epistolario Belgraniano (Academia Nacional de la Historia, 1970), 247.

28 Juan Marchena Fernández, "Reformas borbónicas y poder popular en la América de las Luces. El temor al pueblo en armas a fines del período colonial”, Anales de Historia Contemporánea 8 (1992).

29 Sobre el particular en el Río de la Plata se puede consultar Lyman Johnson, "La conspiración francesa de 1795", en Los talleres de la revolución. La Buenos Aires plebeya y el mundo del Atlántico, 1776-1810 (Buenos Aires: Prometeo Libros, 2013), 203-38; Beatriz Bragoni, "Esclavos insurrectos en tiempos de revolución (Cuyo 1812)", en Negros de la patria. Los afrodescendientes en las luchas por la independencia en el antiguo Virreinato del Río de la Plata, ed. Silvia Mallo e Ignacio Telesca 
portante: la resistencia por parte de esas mismas elites a la pérdida de sus bienes materiales. La movilización de esclavos atentaba claramente contra el derecho a la propiedad. Andrews cita a la junta de Buenos Aires que al asumir el poder dejaba en claro que no podía avanzar en la libertad de los esclavos sin atacar lo “...sagrado de nuestras propiedades...” y que junto a este argumento también apelaban a la incapacidad de los negros de valerse por sí mismos ${ }^{30}$. De esta forma los revolucionarios eludían en un primer momento la cuestión de la abolición de la esclavitud.

Esta cuestión, la resistencia por parte de los propietarios de esclavos a ceder parte de sus propiedades es algo bien documentado para distintos puntos de las Provincias Unidas del Río de la Plata ${ }^{31}$. Lo que no quita que tampoco hayan existido donaciones voluntarias, pero no hay en principio un avance del gobierno revolucionario sobre los propietarios de esclavos. La cuestión de la movilización de hombres de color en los primeros años es una cuestión que resulta espinosa para muchos actores del período.

En 1813, el gobierno de Buenos Aires acepta la creación, en la Intendencia de Salta de una compañía de Pardos y Morenos, de hombres libres por supuesto. El gobernador Intendente, Feliciano Chiclana es quien procedió a armar a estos hombres luego de que el general del Ejército Auxiliar del Perú, Manuel Belgrano, se negara a equipar a las dos compañías de urbanos por considerarlo innecesario. Chiclana alude la presencia de numerosos enemigos en Salta y a la cercanía con el Perú para proceder de este modo. Pero al repasar el expediente, se puede ver este temor o resistencia e incluso el perjuicio del que estábamos hablando:

“..Es bien raro qe. en un Pueblo en qe. hay tanto vecindario y hombres blancos capaces de tomar las armas, se depositen estas en las clases mas inferiores del Estado como son los Pardos y Morenos. Representando como devo la politica de V.E. en la di- 
reccion de los negocios p p. cos creo que el Govrn. Intendente de Salta no acierta en la eleccion que ha hecho, y que como tal debe desaprovarsele la formacion de las Comp.a que propone. Mas si V.E. la estimase, sea al menos con oficiales blancos, al modo con que se ha hecho en la Capital, y en la ciudad de Cordoba segun se me ha asegurado..." 32 .

Sin embargo, más tarde en ese año es posible ver un giro en la política del gobierno. La reunión de la Asamblea del Año XIII significó un parteaguas en la revolución y un giro hacia posturas más radicales, y si bien muchos de sus objetivos principales quedaron truncos, como la declaración de Independencia o la sanción de una Constitución, fue un momento de definición en diferentes planos. Uno de ellos tuvo que ver con la población afromestiza. Y si bien no se abolió la esclavitud, los decretos de Libertad de Vientres y la prohibición del tráfico de hombres fueron muy significativos. El tercer decreto de importancia para la población de afromestizos estableció que el gobierno realizaría un gran rescate de esclavos para reforzar los ejércitos de la revolución. Y esto estaba en línea con uno de los principales objetivos de la Asamblea y de la Logia Lautaro, que buscaba la movilización de todos los recursos disponibles en el Río de la Plata para ganar la guerra en un plazo perentorio ${ }^{33}$.

Según Alejandro Rabinovich, el gobierno puso la atención sobre los esclavos porque más allá de su buena estatura y talla, se creía que serían excelentes reclutas para la Infantería porque existía una cierta simetría entre las normas de la vida cuartelera y las que los regían. El esclavo sería un buen recluta porque tendría parte de su instrucción realizada sobre todo en lo que respecta a la subordinación ${ }^{34}$. Y según Goldberg aunque se apelaba al reclutamiento de esclavos por necesidad, se seguía manteniendo ciertas reservas y por eso se continuó preservando para la gente decente las plazas de oficiales de las nuevas unidades de libertos ${ }^{35}$.

32 AGN, Sala X, Legajo 3-10-6 Ejército Auxiliar del Perú.

33 Marcela Ternavasio, Gobernar la Revolución. Poderes en disputa en el Río de la Plata, 1810-1816 (Buenos Aires: Siglo XXI Editores, 2007).

34 Alejandro Rabinovich, 43.

35 Marta Goldberg, "Afrosoldados de Buenos Aires en armas para defender a sus amos”, en Negros de 
El primer decreto de la Asamblea fue del 31 de mayo de 1813 y comprendía a la ciudad de Buenos Aires y a fines de ese año se extendieron a toda la campaña de Buenos Aires. Contemplaba la compra de esclavos que tuvieran entre 13 y 60 años los que obtendrían la libertad luego de un período de 5 años de servicios ${ }^{36}$. Pero a estas primeras medidas se le fueron sucediendo una serie de disposiciones complementarias que establecieron nuevos rescates para los años siguientes (1815, 1816 y 1818). Según Andrews, el rescate resultó efectivo en términos de dotar a los ejércitos revolucionarios de nuevos reclutas, y que después de la destrucción de los regimientos de pardos y morenos libres, las únicos unidades que quedaron en pie fueron las de libertos ${ }^{37}$. Al menos para la ciudad de Buenos Aires los números son bastante claros. En 1813 se rescataron 1.016 negros. En las fechas siguientes existe una pequeña diferencia entre las cifras que arrojan Goldberg y Andrews que fueron los que principalmente estudiaron este caso. Mientras la primera sostiene que fueron 1.483 entre 1815 y 1818 , el segundo da un número un poco menor para ese mismo período: $1.059^{38}$. Para la cantidad de población negra esclava de Buenos Aires estos números eran importantes. En 1810 los afromestizos serían casi el 30\% de la población de la ciudad de Buenos Aires. Es decir, 9.615 de los cuales solo el 22\% sería libre (2.115). Esto dejaba que 7.500 eran esclavos, y teniendo en cuenta una paridad relativa entre hombres y mujeres, esto nos deja que en 1810 había 3.750 negros esclavos de los cuales podían ser reclutados aquellos que tenían entre 13 y 60 años, por lo que los más de 2.000 que fueron rescatados entre 1813 y 1818 es un número significativo ${ }^{39}$.

Los decretos de la Asamblea también se aplicaron en otros espacios, pero no parecen haber tenido, inicialmente, un impacto de tal magnitud sobre la población afromestiza esclava local. Para uno de los espacios que más datos tenemos es para la Gobernación de Cuyo. En esta jurisdicción en

la Patria. Los afrodescendientes en las luchas por la independencia en el antiguo Virreinato del Río de la Plata, ed. Ignacio Telesca y Silvia Mallo (Buenos Aires: Editorial SB, 2010), 68-69.

36 Marta Goldberg, Afrosoldados de Buenos Aires, 68.

4438 Marta Goldberg, "Afrosoldados de Buenos Aires en armas para defender a sus amos", 70; George Reid Andrews, Los Afroargentinos de Buenos Aires, 140.

39 Las cifras de este párrafo fueron extraídas de los capítulos 3, 4 y 5 de George Reid Andrews, Los Afroargentinos de Buenos Aires. 
1814 se rescataron tan solo 46 esclavos para el Batallón de libertos que se estaba conformando en Buenos Aires y en 1815 se produjo el rescate de otros 23. Lo que es un número muy bajo si tenemos en cuenta que la población negra (esclava y liberta) en Cuyo ascendía a 8.506 personas en $1812^{40}$. Pero esto varió cuando se dio inicio al plan Sanmartiniano y la recluta de esclavos se intensificó. En 1816 fueron rescatadas las dos terceras partes de la esclavatura de la Gobernación de Cuyo y fueron incorporados al Ejército de Los Andes 710 esclavos $^{41}$.

Carecemos de datos de estas características para los espacios por los que se desplazó el Ejército Auxiliar del Perú, pero en principio no parece haberse llevado adelante una recluta de estas características, ni de libertos de ni afromestizos libres. Lo cual llama la atención teniendo en cuenta la composición de las sociedades de esos espacios.

Sara Mata sostiene que luego de la Batalla de Salta, que significó que ese espacio quedara definitivamente en control de la Revolución, se produjo el rescate de esclavos y sobre todo que negros que habían pertenecido a partidarios del Rey fueron incorporados a las fuerzas de la revolución ${ }^{42}$. Sin embargo, no tenemos datos, o cifras concretas sobre esta cuestión. Esta historiadora también es la que nos informa que en 1811 se había conformado en Salta una compañía de Negros Libres en 1811 que se disolvió en 1814, y ya vimos que Alejandro Rabinovich nos informa la participación de una compañía de negros libres en la Batalla de Huaqui y que en 1813 el gobernador Feliciano Chiclana conformó, a pesar de la resistencia del gobierno, una unidad de estas características. Sin embargo, esto parece poco cuando el Censo de 1778 arroja que en la jurisdicción el 45\% de la población es afromestiza (34\% negros libres y $11 \%$ esclavos) ${ }^{43}$. En número reales esto significaba que 3.966 eran afromestizos libres y 1.339, esclavos.

40 Beatriz Bragoni, "Esclavos, libertos y soldados: la cultura política plebeya en Cuyo durante la revolución”, en ¿Y el pueblo dónde está? Contribución para una historia popular de la Revolución de Independencia en el Río de la Plata, ed. Raúl Fradkin, (Buenos Aires: Prometeo Libros, 2008), 133.

41 Beatriz Bragoni, Esclávos, libertos y soldados 135.

42 Sara Mata, "Los negros y esclavos en la guerra por la Independencia. Salta 1810-1821", en Negros de la patria. Los afrodescendientes en las luchas por la Independencia en el antiguo Virreinato del Río de la Plata, ed. Silvia Mallo e Ignacio Telesca (Buenos Aires: SB, 2010), 134.

43 Sara Mata, "Los negros y esclavos en la guerra por la Independencia", 132. 
Pero no solo en la ciudad de Buenos Aires, en Cuyo o en Salta podemos encontrar esta fuerte presencia de negros, mulatos y pardos. El censo de 1778, que fue ordenado por el Virrey Vértiz para todo el territorio bajo su mando, arroja guarismos similares a los de la ciudad capital o incluso mayores a los de Salta para otros espacios. Porque desde mucho antes de ser la capital del Virreinato o un puerto reconocido por la Corona, Buenos Aires actuó como punto intermedio para el comercio legal e ilegal de esclavos entre Brasil y África, principales destinos desde donde provenían los esclavos, y el interior del Virreinato del Río de la Plata y el Alto Perú.

Quizás sea Florencia Guzmán la historiadora que más haya reflexionado sobre la presencia de negros y afromestizos en el interior y sobre todo en el noroeste en los años previos a la revolución. Lo primero que señala esta historiadora es la gran discrepancia que existe entre los censos de 1778, 1789 y 1795 sobre la cantidad de población negra y afromestiza, libre o esclava en estos espacios. La diferencia mayor se encuentra en el abrupto descenso de una medición a la otra. Mientras en 1778 para el Obispado de Tucumán los negros, pardos, mulatos y zambos representaban el 44,5\% de la población del noroeste, siendo posteriormente del 17\% y 16\% respectivamente. Para Guzmán esta diferencia se debe a una subregistración de las poblaciones aborígenes y que los mestizos no fueron contabilizados y fueron a engrosar las cifras de negros. Por eso cree que es erróneo hablar de un descenso y que 17\% sería un número más "real" de negros, pardos y mulatos, libres y esclavos. Pero que en algunos espacios como La Rioja, Catamarca o Tucumán los porcentajes serían muchos mayores superando largamente el 30\%. Igualmente, este $17 \%$ nos arrojaría una población de alrededor de unos veinte mil individuos para la región del noroeste ${ }^{44}$. Guzmán afirma que en todas las jurisdicciones de este espacio:

“...la población blanca fue minoritaria con respecto a la población india y negra (como ya vimos, denominadas en las fuentes de la época como castas y naturales). Los mulatos y pardos generalmente superan a los negros y las poblaciones libres exceden a

44 Florencia Guzmán, “Africanos en la Argentina. Una reflexión desprevenida”, Andes 17 (2006): 2012. 
las esclavas. Se advierte además la preponderancia de una población criolla de color, que se ubica por encima de la africana, y que representa buena parte de la población del noroeste..."45.

Si tenemos en cuenta esto, y lo dicho previamente, la cantidad de unidades militares de hombres de color en el Ejército Auxiliar del Perú no solo parecen relativamente pocas y el número de efectivos también, y aunque por el momento tengamos pocos datos concretos sobre el rescate de negros en el noroeste, ese espacio no parece haber contribuido mucho al esfuerzo de guerra si lo comparamos con Cuyo o Buenos Aires.

Por otro lado, casi que podríamos decir que la composición de nuestro Ejército Auxiliar del Perú no se condice con la sociedad en la que le tocó actuar y de la que también se nutrió para armarse una y otra vez. Pareciera ser mucho más blanco de lo que los censos marcan para la sociedad rioplatense al finalizar el siglo XVIII. Y no solo por la composición social del noroeste. La presencia de negros, mulatos, zambos es muy fuerte en diferentes partes de lo que fue el virreinato del Río de la Plata. En este sentido, es importante recordar que si bien los espacios por lo que se desplazó el Ejército Auxiliar nutrieron de hombres a esta fuerza militar, lo cierto es que también recibió unidades enteras provenientes de Buenos Aires que se habían conformado en la capital con los reclutas enviados desde diferentes partes de las Provincias Unidas del Río de la Plata. 46.

Sin embargo, esto no necesariamente es así. $\mathrm{O}$ al menos es posible introducir ciertos matices. Es probable que estemos ante una subrepresentación de la población afromestiza dentro del Ejército Auxiliar del Perú. Como ya fue señalado por Andrews, junto con la integración de negros en unidades

45 Florancia Guzmán, “Africanos en la Argentina”, 204.

46 Hasta 1816, en que se decidió cambiar la forma de reclutamiento y entrenamiento de los nuevos soldados, los reclutas eran enviados a Buenos Aires donde se integraban a las diferentes unidades militares para luego marchar al destino que les fuera asignado. Esto por supuesto no impedía las unidades que ya se encontraban operacionales la incorporación de hombres en las comunidades locales por las que pasaban o estaban acantonadas. Cfr. Alejandro Rabinovich, "El fenómeno de la deserción en las guerras de la revolución e independencia del Río de la Plata. Elementos cuantitativos y cualitativos para un análisis. 1810-1829", Estudios interdisciplinarios de América Latina y el Caribe 22 (2011): 33-56. 
de blancos, otro fenómeno importante en sí mismo es la clasificación que se hace de los hombres al momento del reclutamiento. Según este historiador, muchos de los que fueron integrados como trigueños y por lo tanto incorporados en las unidades de blancos, puede ser que en realidad hayan sido afromestizos ${ }^{47}$. Lo que no resulta extraño si tenemos presente las dificultades de la clasificación en zonas de contacto interétnico como señala $G_{\text {Guzmán }}^{48}$, fenómeno que es rápidamente verificable si consultamos las fichas de filiación del período como la de este nuevo recluta incorporado al Regimiento de Artillería de la Patria en 1812:

“...José Gabriel Chaves, hijo de padre no conocido y de Francisca Chaves, natural de Santa Rosa, y residente en otro parage, su edad 15 años, su oficio labrador, su religion C.A.R. su estatura cinco pies, sus señales color trigueño, pelo y zejas negras, ojos pardos, nariz corta y afilada, y sin barba, centó plaza pr. el termino de ocho años en esta Ciudad de Cor.va..." 49

Elegimos esta filiación dentro de un conjunto numeroso porque nos marca no sólo la cuestión del color de piel del nuevo recluta, sino también otro elemento importante que colabora en este proceso: no sabemos quién es el padre, o al menos José Gabriel Chaves alude no saber quién es. El mestizaje es un camino muy transitado para alejarse de la esclavitud. Al heredarse por vía materna la esclavitud, numerosos hombres esclavos se casan con mujeres libres (indias, mestizas, pardas) para asegurar la libertad de sus hijos. ${ }^{50} \mathrm{Al}$ no brindarnos datos sobre el padre, José Gabriel Chaves no solo puede hacer valer su condición de hombre libre, sino que además evita ser catalogado como pardo o moreno por sus señas particulares, lo que le permite reforzar su proceso de blanqueamiento y quizás también consolidar un ascenso social en relación a sus padres si nuestras suposiciones son correctas: madre india o mestiza y padre negro quizás esclavo. Pero más allá de esta cuestión, que puede corresponderse como estrategias individuales llevadas adelante por los sectores subalternos para consolidar o variar su lugar en el orden social en el marco del proceso revolucionario,

50 Guzmán, “Africanos en la Argentina. Una reflexión desprevenida ”, 211. 
hay otra cuestión quizás más simple aún: no necesariamente hay coincidencias en las categorías entre los que realizaron los censos y los que están afiliando a los nuevos reclutas, por lo que la clasificación de los mismos sujetos puede ser distinta.

Finalmente, la última cuestión tiene que ver con el esfuerzo o el aporte de hombres de color de las jurisdicciones del noroeste. Si bien es cierto que pareciera no haber una correspondencia tan clara como en el caso de Cuyo, esto también puede ser repensado. Luego de la retirada del Ejército Auxiliar del Perú del Alto Perú tras la derrota de Sipe-Sipe, el esfuerzo por detener el avance de las fuerzas realistas sobre el territorio efectivamente controlado por las Provincias Unidas del Río de la Plata recayó sobre la provincia de Salta. Fueron las milicias y fuerzas veteranas conformadas por su gobernador, Martín Miguel de Güemes, las que hicieron frente una y otra vez a los intentos del Virrey del Perú por avanzar hacia la capital ${ }^{51}$. Sara Mata ha señalado que desde su llegada al gobierno, Güemes promovió la incorporación de negros y afromestizos en las milicias y cuerpos de línea de forma indistinta, sin ningún tipo de segregación. Entonces, mientras en Cuyo los esclavos negros eran incorporados en los Batallones de libertos del Ejército de Los Andes, y el Ejército Auxiliar del Perú se quedaban sin unidades de afromestizos libres y de libertos, en simultáneo los negros, pardos y mulatos de Salta, Jujuy, Orán o Tarija eran incorporados a las fuerzas comandadas por el gobernador de dicha jurisdicción para hacer frente de manera exitosa a la amenaza realista ${ }^{52}$. Igualmente, para poder calibrar de mejor manera esta cuestión sería importante poder ver cómo se realizaron las reclutas en los distintos espacios que nutrieron al Ejército Auxiliar del Perú antes y después de Sipe-Sipe, quiénes fueron reclutados y a dónde fueron destinados.

\section{BALANCE PROVISORIO}

El Ejército Auxiliar del Perú tuvo una destacada y prolongada participación en las llamadas "guerras de independencia" en el Río de la Plata. En

51 Sobre el particular se puede consultar Sara Mata, "Salta y la guerra de Independencia en los Andes Meridionales", Jahrbuch fur Geschichte Lateinamerikas 41 (2004): 223-45; Sara Mata, Los gauchos de Güemes. Guerras de Independencia y conflicto social (Buenos Aires: Sudamericana, 2008).

52 Sara Mata, "Los negros y esclavos en las guerras por la Independencia. Salta 1810-1821", 135. 
importantes momentos fungió como la principal fuerza militar de los gobiernos revolucionarios instalados en Buenos Aires desde mayo de 1810. $\mathrm{Y}$ aunque hemos avanzado mucho en su conocimiento, en su análisis, sobre ciertos temas seguimos sin trabajos que nos permitan su comprensión. Uno de ellos es la participación de negros, pardos y mulatos, libres o esclavos, en esta fuerza militar. Por esa razón, en este artículo nos propusimos avanzar en la cuestión con la mera pretensión de construir un escenario sobre el cual trazar nuevas líneas de trabajo. Teniendo en cuenta esto, nos propusimos como primer objetivo tratar de identificar efectivamente cuántos fueron los afromestizos que participaron del Ejército Auxiliar del Perú a lo largo de sus campañas y cómo fueron integrados a esta fuerza. Y lo que pudimos observar en relación a esta cuestión es que el número de estos hombres en el Ejército Auxiliar siempre fue relativamente bajo, que solo en momentos puntuales, como en la segunda campaña al Alto Perú en las previas de las Batallas de Vilcapugio y Ayohuma, su presencia alcanzaba al 30\% del total de los efectivos totales de dicha fuerza. Lo cual contrasta con la cantidad de negros, pardos y morenos que tuvo el Ejército de Los Andes antes de iniciar su campaña hacia Chile.

Por otro lado, tratamos de analizar esta cuestión en función de las políticas de reclutamiento implementadas por los gobiernos de la revolución y la cantidad de población negra, mulata y parda movilizada en relación a la cantidad de gente de color que vivía en el Río de la Plata hacia 1810. Aunque aquí nuestra aproximación fue más bien a partir de inferencias por la falta de números concretos sobre la movilización de hombres de color en muchas de las jurisdicciones de las Provincias Unidas, la impresión es que el reclutamiento parece haber tenido dos momentos: uno previo a la Asamblea del Año XIII donde solo se reclutaron hombres libres y uno posterior donde se dio paso a la incorporación de esclavos. Y a su vez que este proceso parece haber sido más intenso en Cuyo o Buenos Aires que en los espacios por los que efectivamente se desplazó esta fuerza militar. No obstante en este sentido, es posible ver que en realidad estemos ante un proceso de invisibilización o de subregistración. Y a su vez, la bibliografía existente también nos advierte que para algunos espacios, como el Salto-jujeño desde 1815, hay un proceso de integración de la población de color en las milicias y fuerzas de línea en pie de igualdad con la población blanca lo que dificulta calibrar esta cuestión de forma correcta con las fuentes con las que disponemos. 
A partir de lo relevado es que creemos posible plantear una agenda de investigación que apunte a avanzar en completar los espacios en blanco dejados a lo largo del trabajo y poner a prueba algunas de las hipótesis o explicaciones parciales que fuimos esbozando a lo largo del texto. A su vez, teniendo en cuenta esto, es posible plantearse en el medio plazo otros objetivos que busquen comprender cómo fue el comportamiento de estos hombres en el Ejército desde lo militar, pero también desde lo relacional o la formación política, en pos reconstruir cómo la guerra y su participación en ella moldeó, afectó o varió las condiciones de vida de esta parte importante de la población rioplatense.

\section{Bibliografía}

\section{Fuentes Primarias}

\section{Archivo}

Archivo General de la Nación (AGN), Buenos Aires, Argentina, Sala X Legajos: 21-9-1; 3-8-6-; 3-10-6; 4-1-3; 4-1-6; 4-2-2; 40-8-6 Servicio Histórico del Ejército (SHE), Buenos Aires, Argentina Legajos: Ejército Auxiliar del Perú, C5; Estados de Fuerza Expedición de Auxilio a las Provincias Interiores, Ejército Auxiliar del Perú, C7.

\section{Fuentes Secundarias}

Academia Nacional de la Historia. Epistolario Belgraniano. Academia Nacional de la Historia, 1970.

Andrews, George Reid. Los Afroargentinos de Buenos Aires. 1er ed. Argentina: Ediciones de La Flor, 1989.

Bernand, Carmen. "Los olvidados de la revolución: el Río de la Plata y sus negros". Nuevo Mundo Mundos Nuevos. Nouveaux mondes Mondes nouveaux - Novo Mundo Mundos Novos - New world New worlds, (2010). https://doi.org/10.4000/nuevomundo.58416

Bragoni, Beatriz. "Esclavos insurrectos en tiempos de revolución (Cuyo 1812)". En Negros de la patria. Los afrodescendientes en las luchas por la independencia en el antiguo Virreinato del Río de la Plata, editado por Silvia Mallo e Ignacio Telesca. Buenos Aires: SB, 2010, 113-29 
Bragoni, Beatriz. "Esclavos, libertos y soldados: la cultura política plebeya en Cuyo durante la revolución”. En ¿Y el pueblo dónde está? Contribución para una historia popular de la Revolución de Independencia en el Río de la Plata, editado por Raúl Fradkin . Buenos Aires: Prometeo Libros, 2008, 107-49

Davio, Marisa. "El proceso de militarización en Tucumán: experiencias e identidades de los sectores populares". Historia y Memoria (2011): 93-96.

Di Meglio, Gabriel. "Soldados de la Revolución. Las tropas porteñas en la guerra de independencia (1810-1820)". Anuario IHES 18 (2003).

Fradkin, Raúl. “Tradiciones militares coloniales. El Río de la Plata antes de la revolución”. En Experiências nacionais, temas transversais: subsídios para uma história comparada da América Latina, editado por Flavio Heinz. São Leopoldo: Editora Oikos, 2009.

Garavaglia, Juan Carlos. "Ejército y milicia: los campesinos bonaerenses y el peso de las exigencias militares, 1810-1860”. Anuario IHES 18 (2003): 153-87.

Goldberg, Marta. "Afrosoldados de Buenos Aires en armas para defender a sus amos". En Negros de la Patria. Los afrodescendientes en las luchas por la independencia en el antiguo Virreinato del Río de la Plata, editado por Ignacio Telesca y Silvia Mallo, Buenos Aires: Editorial SB, 2010 63-85.Guzmán, Florencia. Africanos en la Argentina. Una reflexión desprevenida. Andes 17 (2006): 197-238.

Guzmán, Florencia. "Afroargentinos, guerra y política, durante las primeras décadas del siglo XIX. Una aproximación hacia una historia social de la revolución”. Estudios Históricos - CDHRPyB 11 (2013).

Johnson, Lyman. “La conspiración francesa de 1795”. En Los talleres de la revolución. La Buenos Aires plebeya y el mundo del Atlántico, 1776-1810. Buenos Aires: Prometeo Libros, 2013, 203-38.

Luqui-Lagleyze, Julio. "La organización general y particular del Ejército de las Provincias Unidas del Río de la Plata, 1810-1820”. En Guerra de la Independencia. Una nueva versión, editado por Miguel Ángel De Marco. Buenos Aires: Emecé Editores, 2013, 157-93.

Lynch, John. San Martín. Soldado argentino. Héroe americano. Barcelona: Crítica, 2009. 
Macchi, Virginia. "Guerra y política en el Río de la Plata: el caso del Ejército Auxiliar del Perú (1810-1811)". Anuario de la Escuela de Historia Virtual 3 (2012): 78-96.

Mallo, Silvia e Ignacio Telesca. Negros de la patria. Los afrodescendientes en las luchas por la Independencia en el antiguo Virreinato del Río de la Plata. La Plata: SB, 2010.

Marchena Fernández, Juan. "Reformas borbónicas y poder popular en la América de las Luces. El temor al pueblo en armas a fines del período colonial". Anales de Historia Contemporánea 8 (1992).

Mata, Sara. Los gauchos de Güemes. Guerras de Independencia y conflicto social. Buenos Aires: Sudamericana, 2008.

Mata, Sara. "Los negros y esclavos en las guerras por la Independencia. Salta 1810-1821”. En Negros de la patria. Los afrodescendientes en las luchas por la Independencia en el antiguo Virreinato del Río de la Plata, editado por Silvia Mallo e Ignacio Telesca. Buenos Aires: SB, 2010 131-47.

Mata, Sara. "Salta y la guerra de Independencia en los Andes Meridionales”. Jahrbuch fur Geschichte Lateinamerikas 41 (2004): 223-45.

Mitre, Bartolomé. Historia de Belgrano y de la independencia argentina. 1a ed. Buenos Aires: El Ateneo, 2014.

Morea, Alejandro. "El Ejército Auxiliar del Perú y la revolución en el Río de la Plata". En Belicosas Fronteiras. Contribuições recentes sobre política, economia e escravidão em sociedades americanas (século XIX), editado por Jonas Vargas. Porto Alegre: FI, 2017, 67-89.

Morea, Alejandro. "El proceso de profesionalización del Ejército Auxiliar del Perú durante las guerras de independencia. Revista Quinto Sol 15, No. 2 (2011): 73-96.

Morea, Alejandro. "Perfil de los oficiales del Ejército Auxiliar del Perú en el contexto revolucionario rioplatense, 1810-1820”. Hib: Revista de Historia Iberoamericana 8, No. 2 (2015): 102-31. https://doi. org/10.3232/HIB.2015.V8.N2.05

Morea, Alejandro. "Soldados para la Independencia. Algunas notas sobre las características del cuerpo de oficiales del Ejército Auxiliar del Perú". Nuevo Mundo Mundos Nuevos [En línea] (2013). tp:// nuevomundo.revues.org/65195; DOI: 10.4000/nuevomundo.65195 
Rabinovich, Alejandro. "El fenómeno de la deserción en las guerras de la revolución e independencia del Río de la Plata. Elementos cuantitativos y cualitativos para un análisis. 1810-1829". Estudios interdisciplinarios de América Latina y el Caribe 22 (2011): 33-56.

Rabinovich, Alejandro. “Obedecer y comandar. La formación de un cuerpo de oficiales en los ejércitos revolucionarios del Río de la Plata, 1810-1820”. Estudios Sociales (2011).

Rabinovich, Alejandro. Ser soldado en las Guerras de Independencia. La experiencia cotidiana de la tropa en el Río de la Plata, 1810-1824. Buenos Aires: Editorial Sudamericana, 2013.

Rabinovich, Alejandro M. Anatomía del pánico. La batalla de Huaqui, o la derrota de la revolución (1811). Buenos Aires: Sudamericana, 2017.

Rondeau, José. Autobiografía. Ciudad: Comercio del Plata, 1846.

Ruiz Moreno, Isidoro. Campañas militares argentinas. Argentina: Emecé Editores, 2008.

Soria, Diego Alejandro. "Las grandes unidades de batalla". En Guerra de la Independencia. Una nueva versión, editado por Miguel Ángel De Marco,. Buenos Aires: Emecé Editores, 2013, 109-33.

Ternavasio, Marcela. Gobernar la Revolución. Poderes en disputa en el Río de la Plata, 1810-1816. Buenos Aires: Siglo XXI Editores, 2007.

Para citar este artículo: Morea, Alejandro. "Negros, pardos y morenos en el Ejército Auxiliar del Perú (1810-1820)", Historia Caribe Vol. XIV No. 35 (Julio-Diciembre 2019): 25-54. DOI: http:/ / dx.doi.org/10.15648/ hc.35.2019.2 